\title{
МАТЕМАТИЧЕСКОЕ ИМИТАЦИОННОЕ МОДЕЛИРОВАНИЕ ЗЕРНОСУШИЛОК КАК ОСНОВА РАЗРАБОТКИ ЭФФЕКТИВНЫХ СИСТЕМ УПРАВЛЕНИЯ
}

\author{
Степанов М.Т. ${ }^{1}$, Еремин М.А. ${ }^{2}$, Веридусов П.А. ${ }^{2}$ \\ ${ }^{1}$ Одесская национальная академия пищевых технологий, г. Одесса, stepanov1978@mail.ru, \\ ${ }^{2}$ Компания С-инжиниринг, г. Одесса
}

Copyright (C) 2014 by author and the journal “Automation technological and business - processes".

This work is licensed under the Creative Commons Attribution International License (CC BY).

http://creativecommons.org/licenses/by/4.0/

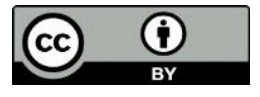

\begin{abstract}
Аннотация
Разработана в среде MATLAB имитационная модель зерносушилки, предназначенная для синтеза систем автоматического управления. Она включает в себя комплекс моделей: модель подготовки сушильного агента, модели тепло-массообменых процессов в зонах сушки и охлаждения, модель эффективности функционирования. Результаты тестирования подтверждают ее адекватность как модели объекта управления.
\end{abstract}

\section{Abstract}

The simulation model of grain dryer in the MATLAB environment was developed. The simulation model is designed for the synthesis of systems of automatic control. It includes complex of models. Such as the model of preparation of drying agent, the models of thermo-mass-exchanged processes are in the zones of drying and cooling, the model of efficiency of functioning. Testing results confirm her adequacy as models of object control.

Ключевые слова

Имитационная модель, шахтная зерносушилка, объект управления, система автоматического управления.

\footnotetext{
Энергетическая эффективность процессов сушки зерна обуславливается двумя основными факторами. Вопервых, конструктивными особенностями и характеристиками зерносушильного агрегата, в том числе режимами сушки, которые были заложены на этапе его разработки. Во-вторых, уровнем интеллекта [1] систем автоматического управления (САУ) процессом, которые должны обеспечить выполнение материальных и энергетических балансов процесса в непрерывно изменяющихся условиях на энергетически выгодных уровнях. Очевидно, что упрощенные подходы к разработке САУ не позволяют выявить и затем реализовать лучшие решения. Применение имитационных математических моделей процессов сушки с высоким уровнем адекватности их статических и, главное, динамических свойств, позволит найти эти решения в ходе целенаправленных интерактивных машинных экспериментов с этими моделями. Основу имитационных моделей составляют математические модели процессов сушки зерна разработанные в [2-4].
}

Имитационная модель сушилки реализована в среде MATLAB. Она включает в себя объединенные в 


\section{1 ПИТАННЯ ТЕОРІЇ, МЕТОДИ ТА АЛГОРИТМИ ЕФЕКТИВНОГО АВТОМАТИЧНОГО УПРАВЛІННЯ ОБ'ЄКТАМИ ХІМІКО-ТЕХНОЛОГІЧНОГО ТИПУ}

единую структуру комплекс моделей: модель подготовки сушильного агента (СА), включая модель тепломассообменных процессов в топке и смесителе, модели тепло-массообменных процессов в зонах сушки и охлаждения, модель эффективности функционирования. Структурная схема модели шахтной сушилки ДСП32от приведена на рис. 1.

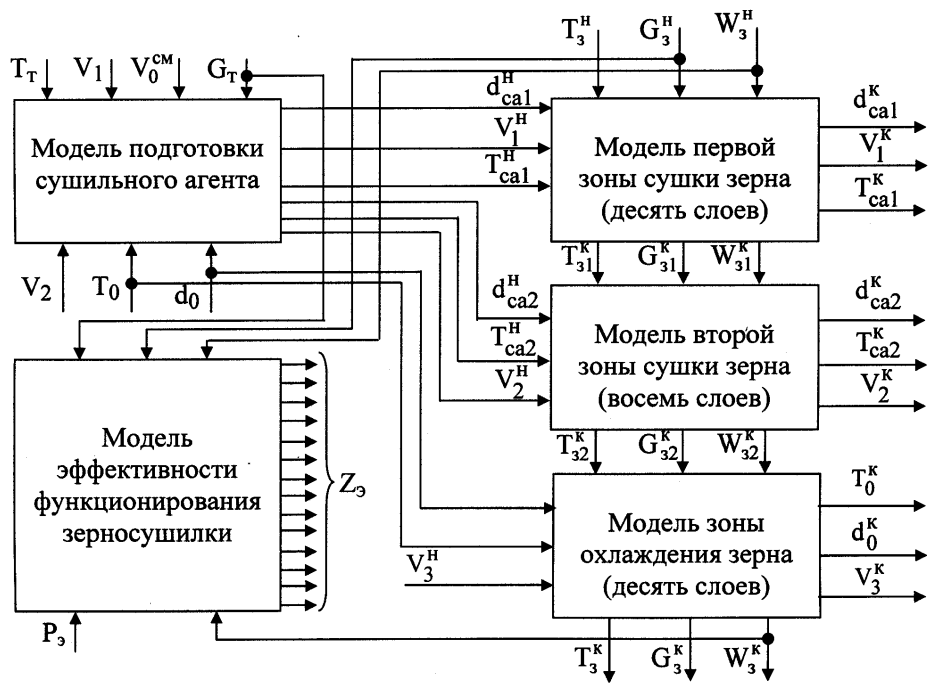

Рис. 1 - Структурная схема модели шахтной зерносушилки ДСП-32от

Принятые обозначения: $T, W, d, V, G, P_{\ni}$ - соответственно температура, влажность, влагосодержание, объемный расход, массовый расход, электрическая мощность; нижние индексы: «з»-зерно, «са»-сушильный агент, «т» - топливо, «о»-воздух окружающей среды, «1, 2, 3»-номера зон;

верхние индексы: «н», «к»-начальные и конечные значения параметров

Модель подготовки СА учитывает нелинейные свойства топки, зависимость параметров СА от параметров воздуха окружающей среды и топлива сжигаемого в топке, особенности взаимосвязи и динамики изменения температур СА на выходе из топки и смесителя. В частности в модели отражено изменение температуры СА на выходе из топки, как за счет быстрого прогрева воздуха внутри топки, так и за счет более медленного прогрева внутренних частей стен топки. Структурная схема имитационной модели подготовки СА в обобщенном виде (без раскрытия структуры ее отдельных подсистем) приведена на рис. 2, а иллюстрация работы модели на рис. 3.

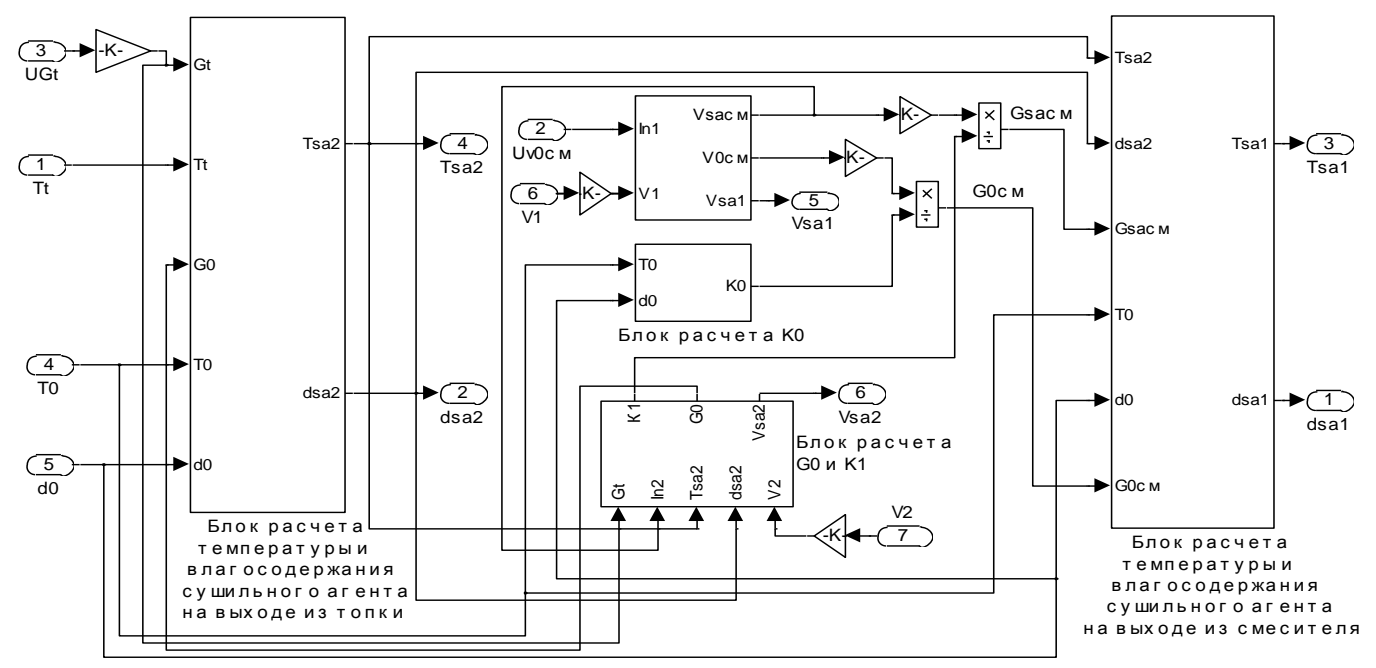

Рис. 2 - Обобщенная структурная схема имитационной модели подготовки СА 


\section{I ПИТАННЯ ТЕОРІЇ, МЕТОДИ ТА АЛГОРИТМИ ЕФЕКТИВНОГО АВТОМАТИЧНОГО} УПРАВЛІННЯ ОБ'ЄКТАМИ ХІМІКО-ТЕХНОЛОГІЧНОГО ТИПУ
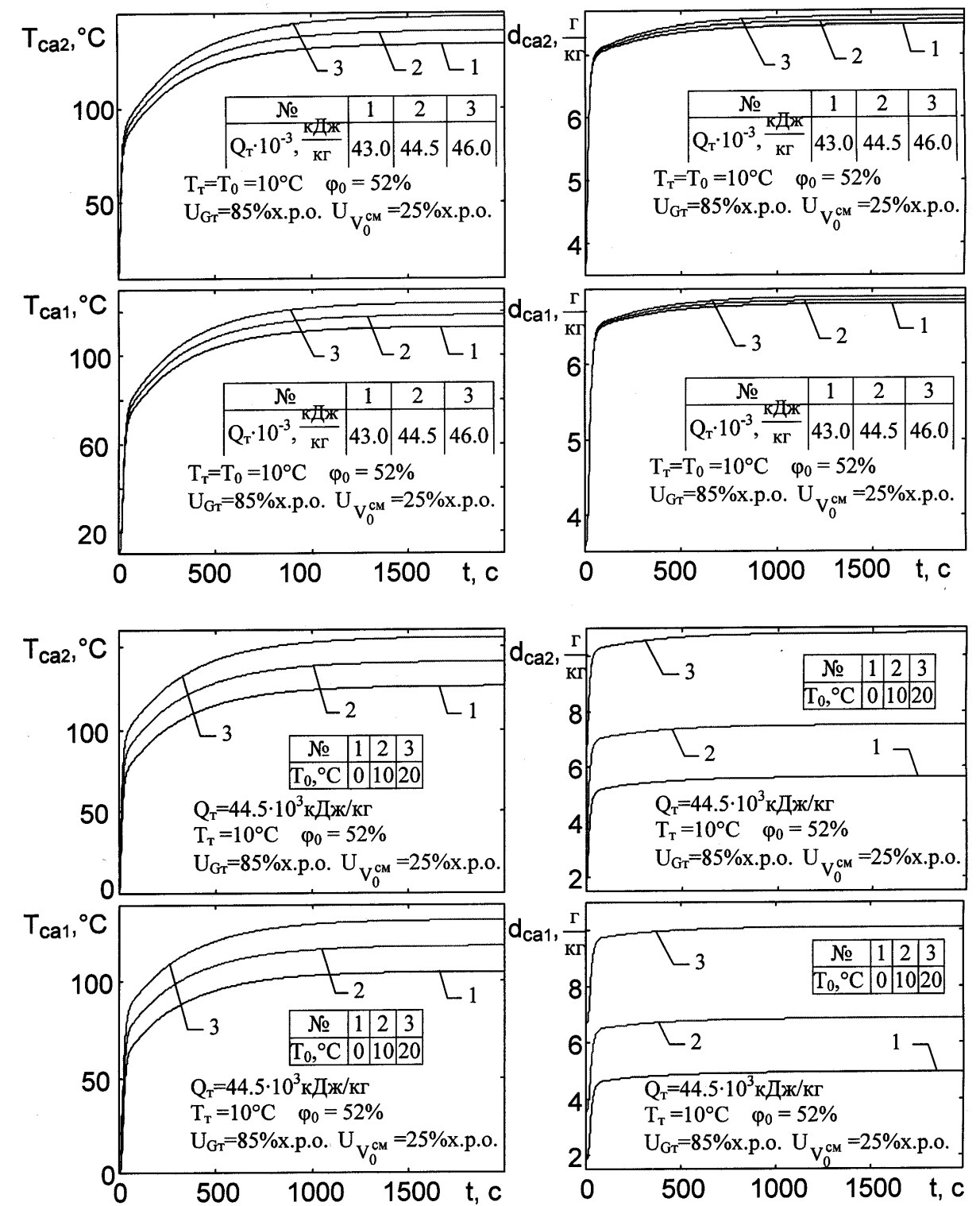

Рис. 3 - Иллюстрация работы модели формирования СА: динамика изменения температуры и влагосодержания СА на выходе из топки и смесителя во время запуска сушилки в работу при различных значениях параметров топлива и воздуха окружающей среды

Модели тепло-массообменных процессов, происходящих в зонах сушки и охлаждения, описывают динамику изменения параметров зерна и СА при их движении в шахтах зерносушилки. Каждая зона разбивается на элементарные слои, высота которых равна шагу расположения коробов. Такой подход позволяет получить модели зон с распределенными параметрами по высоте сушилки и адекватно отразить в модели динамику процессов, а специальный алгоритм расчета времени пребывания зерна в каждом слое - корректно моделировать работу сушилки в условиях изменяющейся производительности. Это очень важно для разработки САУ. Кроме того, эти модели учитывают неравномерность распределения массовых расходов СА по высоте шахт. При этом обеспечивается соответствие между массовым расходом сухого СА, поступившего в зону и ушедшего из нее. В модели также учтены затраты энергии на отрыв влаги от зерна и изменение скорости удаления влаги из зерна по мере его высушивания. Изменение скорости сушки достигается за счет приближенного воспроизведения двух периодов сушки. Первый, когда водяной пар в воздухе непосредственно над зерном находится в состоянии насыщения и второй, когда, при достижении влажностью зерна некоторого 


\section{$\underline{1}$ ПИТАННЯ ТЕОРІЇ, МЕТОДИ ТА АЛГОРИТМИ ЕФЕКТИВНОГО АВТОМАТИЧНОГО УПРАВЛІННЯ ОБ'ЄКТАМИ ХІМІКО-ТЕХНОЛОГІЧНОГО ТИПУ}

критического значения, относительная влажность воздуха над зерном уменьшается по мере удаления влаги из зерна. Отметим, что в модели предусмотрено ограничение относительной влажности отработанного СА.

Структурная схема имитационной модели элементарного слоя зерна в обобщенном виде приведена на рис. 4, иллюстрация работы модели слоя - на рис. 5, а модели первой зоны сушки, включая динамику изменения температуры и влажности зерна, а также массового расхода СА для каждого слоя в переходных режимах работы зерносушилки - на рис. 6.

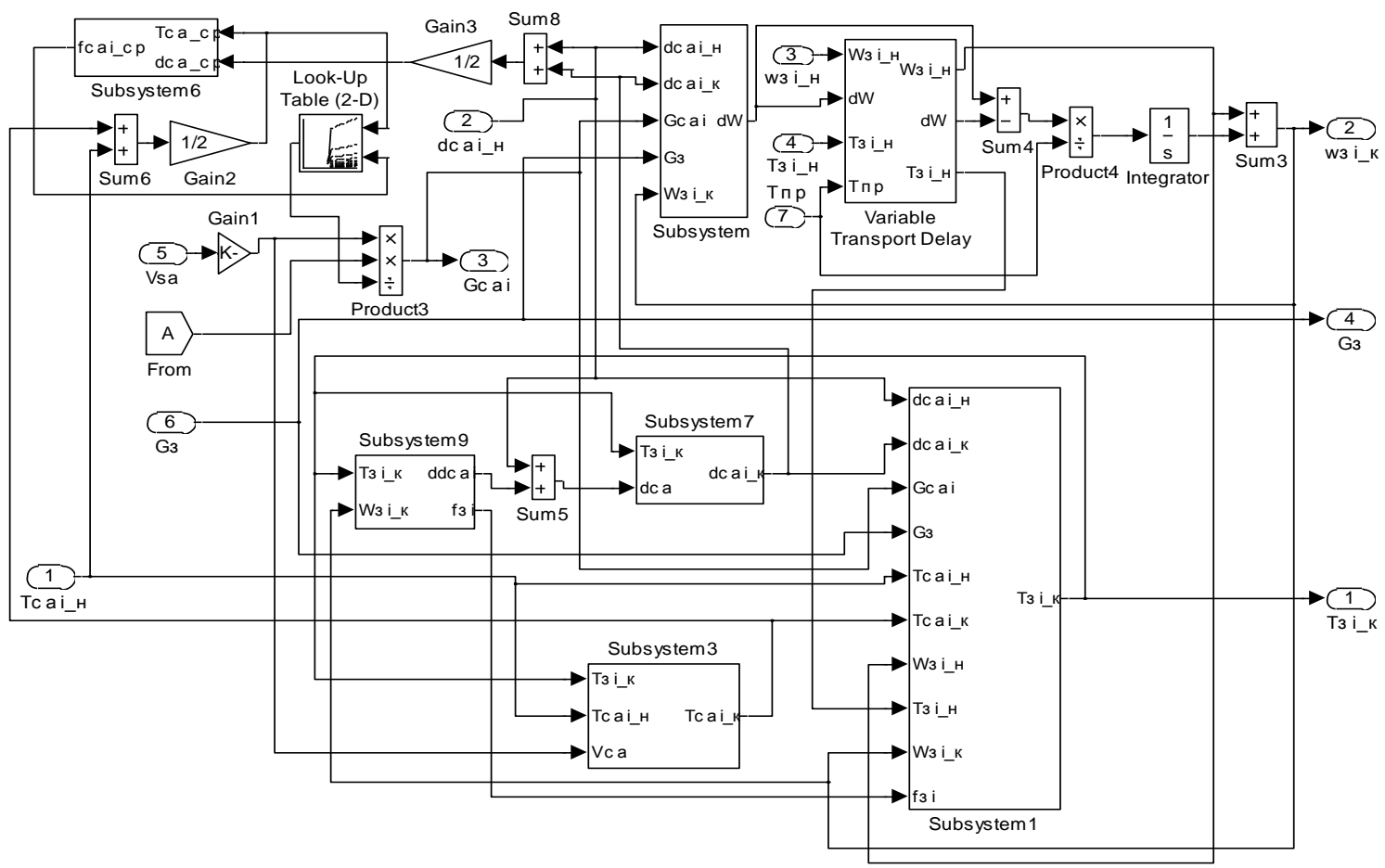

Рис. 4 - Обобщенная структурная схема имитационной модели элементарного слоя зерна

Модель эффективности функционирования осуществлет расчет основных технико-экономических показателей работы зерносушилки (масса просушенного зерна, средняя производительность, суммарные и удельные затраты топлива и электроэнергии), как в плановых единицах, принятых технологами, так и в физических.

Рис. 7 иллюстрирует работу модели шахтной зерносушилки ДСП-32от вцелом. На нем показана динамика изменения температуры и влажности зерна по слоям в двух зонах сушки и зоне охлаждения при изменении производительности сушилки. Обозначения (не рассмотренные в рис. 1): $\tau_{\text {пр }}$ - время пребывания зерна в сушилке; $T_{3 i, j}^{\kappa}, W_{3 i, j}^{\kappa}$ - температура и влажность зерна в і-той зоне ј-того слоя.

Приведенный фрагмент показывает возможности применения модели для разработки наиболее сложного в динамическом отношении канала регулирования САУ - канала регулирования влажности зерна за счет изменения производительности зерносушилки.

Результаты, полученные в ходе тестирования отдельных моделей и модели зерносушилки ДСП-32от вцелом, подтверждают ее адекватность как модели объекта управления.

\section{Литература}

1. Хобин В. А. Интеллектуализация алгоритмов управления - экономичный путь повышения эффективности производства / В. А. Хобин // Наук. пр. ОДАХТ. - Одеса : 2002. - Вип. 24. - С. $405-407$.

2. Жидко В. И. Зерносушение и зерносушилки / В. И. Жидко, В. А. Резчиков, В. С. Уколов // М. : Колос, 1982. - 239 c.

3. Птицын С. Д. Зерносушилки / С. Д. Птицын // М. : Машиностроение, 1966. - 212 с.

4. Краусп В. Р. Автоматизация послеуборочной обработки зерна / В. Р. Краусп // М. : Машиностроение, 1975. - 277 c. 


\section{$\underline{1}$ ПИТАННЯ ТЕОРІЇ, МЕТОДИ ТА АЛГОРИТМИ ЕФЕКТИВНОГО АВТОМАТИЧНОГО} УПРАВЛІННЯ ОБ'ЄКТАМИ ХІМІКО-ТЕХНОЛОГІЧНОГО ТИПУ

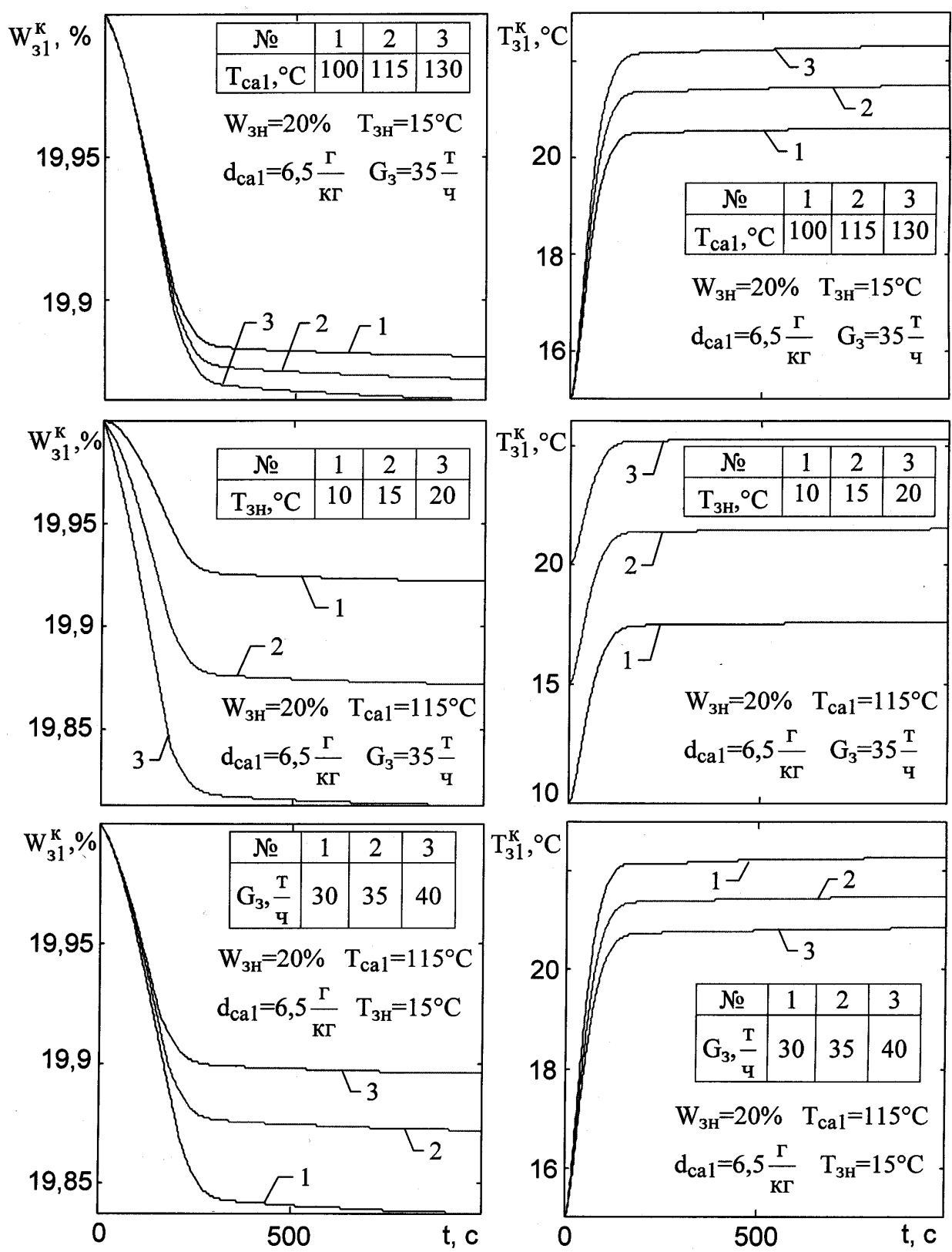

Рис. 5 - Иллюстрация работы модели элементарного слоя зерна в сушилке: динамика изменения температуры и влажности зерна на выходе из элементарного слоя при различных условиях сушки 


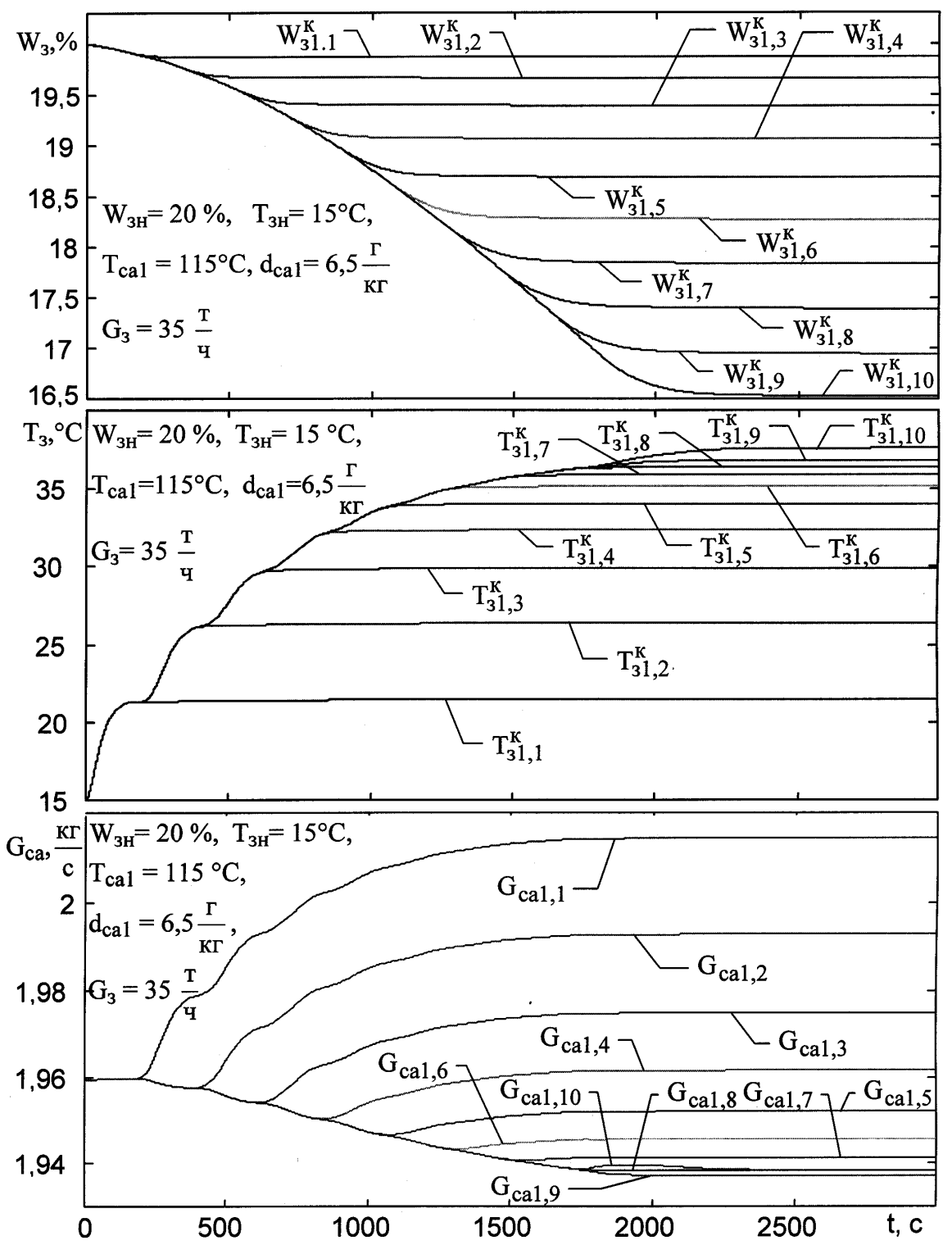

Рис. 6 - Иллюстрация работы модели первой зоны сушки зерна: динамика изменения температуры и влажности зерна, а также массового расхода СА для каждого слоя в переходных режимах работы зерносушилки 


\section{1 ПИТАННЯ ТЕОРІЇ, МЕТОДИ ТА АЛГОРИТМИ ЕФЕКТИВНОГО АВТОМАТИЧНОГО} УПРАВЛІННЯ ОБ'ЄКТАМИ ХІМІКО-ТЕХНОЛОГІЧНОГО ТИПУ

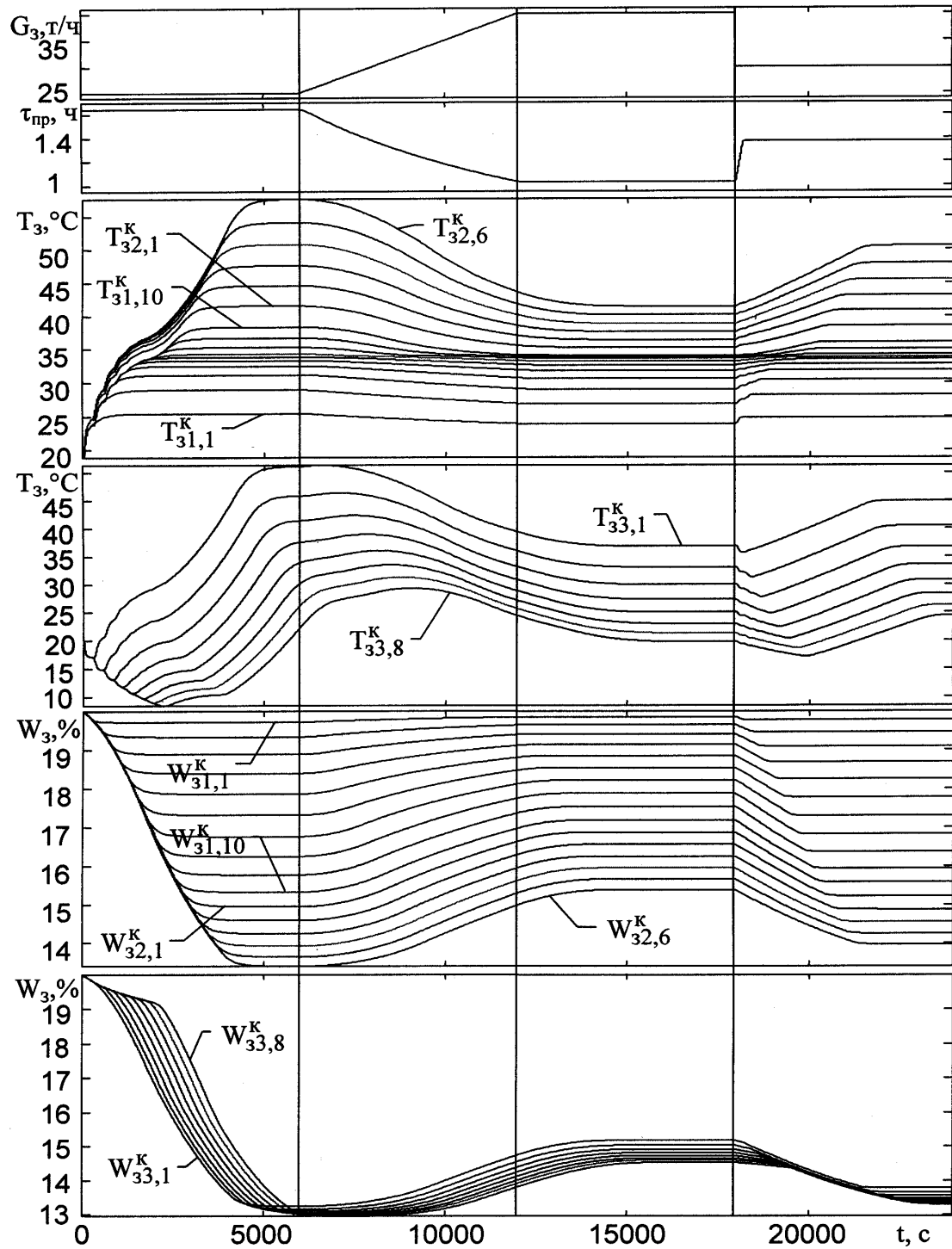

Рис. 7 - Иллюстрация работы модели шахтной зерносушилки вцелом: динамика изменения температуры и влажности зерна по слоям в двух зонах сушки и зоне охлаждения при изменении производительности сушилки 